\title{
A FORMAÇÃO DE PROFESSORES NA PERSPECTIVA DA EDUCOMUNICAÇÃO
}

\section{LA FORMACIÓN DE PROFESORES EN LA PERSPECTIVA DE LA EDUCOMUNICACIÓN}

\section{THE TRAINING OF TEACHERS IN THE PERSPECTIVE OF EDUCOMMUNICATION}

Isabel Pereira dos SANTOS $^{1}$

RESUMO: Este trabalho apresenta as convergências entre os fundamentos da educação emancipatória e os fundamentos da Educomunicação. Mostra a relevância da aplicação das duas vertentes no processo de formação dos professores e apresenta as áreas da Educomunicação como possibilidades de atuação no universo das práticas educomunicativas.

PALAVRAS-CHAVE: Educação emancipatória. Educomunicação. Formação de professores.

RESUMEN: Este trabajo presenta las convergencias entre los fundamentos de la educación emancipatoria y los fundamentos de la Educomunicación. Muestra la relevancia de la aplicación de las dos vertientes en el proceso de formación de los profesores y presenta las áreas de la Educomunicación como posibilidades de actuación en el universo de las prácticas educomunicativas.

PALABRAS-CLAVE: Educación emancipatoria. Educomunicación. Formación de professores.

ABSTRACT: This paper presents the convergences between the foundations of emancipatory education and the foundations of Educommunication. It shows the relevance of the application of both aspects in the teacher training process and presents the areas of Educommunication as possibilities of action in the universe of educommunication practices.

KEYWORDS: Emancipatory education. Educommunication. Teacher training.

${ }^{1}$ Universidade de São Paulo (USP) - São Paulo - SP - Brasil. Doutora em Educação. Pesquisadora colaboradora do Núcleo de Comunicação e Educação da Escola de Comunicações e Artes da Universidade de São Paulo - ECA/USP. Email: isabelps@gmail.com 


\section{Introdução}

A reflexão sobre a educação emancipatória, enquanto promotora da autonomia do sujeito social, faz emergir questões estruturais sobre a participação efetiva dos agentes sociais na realidade que os cerca, e admite como um dos princípios fundantes o diálogo entre os agentes, de forma que a partir daí se estabeleçam análises críticas que permitam abertura de consciências e novas visões de mundo. Nesta perspectiva, o lócus da educação emancipatória ou problematizadora são os espaços formais, não-formais e informais. De acordo com Viana (2005):

A emancipação, na perspectiva de Adorno, não se refere apenas ao indivíduo como entidade isolada, mas fundamentalmente como um ser social. Ela é pressuposto da democracia e se funda na formação da vontade particular de cada um, tal como ocorre nas instituições representativas. É preciso supor, para evitar um resultado irracional, que cada um possa se servir de seu próprio entendimento. A emancipação é a formação para a autonomia, mas ela só pode ser bem sucedida se for um processo coletivo, já que na nossa sociedade a mudança individual não provoca necessariamente a mudança social mas esta é precondição daquela. A educação deve contribuir, portanto, para o processo de formação e emancipação, contribuindo para criar condições em que os indivíduos, socialmente, conquistem a autonomia. (VIANA, 2005, p.5)

Esta reflexão mostra a emancipação como algo próximo da solidariedade e que deve ser aprendido no início da vida, nas relações sociais, na troca com o outro, na elaboração de ações comprometidas com o social. Este movimento é observado, dentre outras instituições, na escola, espaço formal, privilegiado enquanto local de ações coletivas e transformadoras. Para que estas ações ganhem sentido, a figura dos agentes educacionais precisa ser revista constantemente como protagonista deste processo.

Viana (2005) destaca, dentre outros, a relevância das ações educativas coletivas - com caráter emancipatório - para que ocorram a transformações pessoais, sociais, e em decorrência, as transformações locais e globais. Nesta esteira torna-se mister incluir tais temáticas, de forma efetiva, nas formações de professores. No contexto nacional tais ações visam ao respeito à democracia e aos valores sociais.

O docente comprometido com sua formação/transformação estará atento a mudanças contemporâneas e certamente irá investir em formação e pesquisas em inovações científicas, culturais e dinâmicas de ensino. Nesta perspectiva, o trabalho educacional pautado no acompanhamento, análise, discernimento, reflexões sobre o cotidiano compartilhadas com seus estudantes, propiciam trocas e debates 
transformadores que ampliam as perspectivas culturais, políticas e éticas dos mesmos. Segundo Fagundes (2011):

Em uma proposta educacional emancipatória, o exercício do aprofundamento da criticidade sobre o que somos e sobre o mundo em que vivemos geram necessidades que nos impulsionam a buscar respostas para o que não conhecemos e constrói um imaginário como subjetivação da ação discente-docente, o qual tem como ponto de partida e de retorno à realidade concreta, como forma de conhecimento/ação/intervenção. (FAGUNDES, 2011, p. 173).

Em sua tese, cujo objeto é a análise de trabalhos de pesquisas educacionais, Gamboa discorre sobre a relação dialética entre a realidade e a produção científica e destaca que:

A realidade é entendida como um todo concreto que tem suas propriedades, sua estrutura e seu desenvolvimento que, inclusive, se refletem sobre princípios epistemológicos e aspectos metodológicos da produção científica. A relação entre o todo concreto e a produção científica é uma relação dialética, de mútua implicância. O conhecimento deve partir do real concreto para alcançar algo novo. Pisando no chão firme da realidade, caminha-se em direção a algo melhor. Assim, o concreto é, ao mesmo tempo, o ponto de partida e, sob forma diferente, o ponto de chegada. (GAMBOA, 1998, p.6)

A intenção de Gamboa é investigar as bases epistemológicas no interior das pesquisas no âmbito da Educação, relacionando-as com as condições sócio-históricas e avaliar os resultados “à luz de necessidades e objetivos sociais". Desta feita, implícita está a busca por aspectos e ações emancipatórias em tais pesquisas. Apresenta-se, assim, uma preocupação não só com a qualidade, mas com as implicações e transformações sociais decorrentes.

A pesquisa etimológica do termo "emancipação" cuja origem do latim: "exmancipium" sugere a ideia de indivíduo liberto, independente, autônomo. Nesta esteira é pertinente pensar em um trabalho conjunto entre discentes e docentes emancipados e imbuídos na construção do conhecimento de forma solidária, respeitosa, com vistas à construção da cidadania. Segundo Gadotti:

Uma perspectiva emancipatória da educação e do trabalho deve desenvolver a capacidade de pensar criticamente a realidade e promover a justiça e a solidariedade, fundada na ética, e respeitando a dignidade e a autonomia do educando. Daí a importância estratégica do professor como intelectual transformador e a escola como um espaço de contestação e de construção de uma visão crítica da sociedade, formando para o exercício da cidadania desde a infância. A educação pode ser entendida e praticada 
tanto como um processo de formação para manter a sociedade quanto para transformá-la. Numa perspectiva emancipatória a educação é entendida como problematização da realidade visando à sua transformação. A educação emancipadora é o oposto da educação bancária, uma educação voltada para a fabricação de mão-de-obra para satisfazer as necessidades do mercado. (GADOTTI, 2012, p.2)

Os estudos de Sánchez Gamboa (1998), Viana (2005), Fagundes (2011), e Gadotti (2012) destacam a importância do processo de criação do novo sujeito em face da interação, pesquisa e ações provindas da educação emancipatória, de forma que tal sujeito seja protagonista de transformações significativas no âmbito social.

\section{Educomunicação e as práticas emancipatórias}

Nesta esteira, pesquisas realizadas pelo Núcleo de Educomunicação da Escola de Comunicações e Artes da Universidade de São Paulo - NCE/ECA/USP, revelam o processo de consolidação de um novo campo de intervenção social que reconhece a importância da inter-relação comunicação/educação, denominado Educomunicação.

Nesta interface entre a comunicação e a educação, dentre outras, as propostas de formação do docente pesquisador ganham forma e se estabelecem como estratégia de aprofundamentos de estudos sobre o espaço escolar como um todo, sobre a comunidade educacional, sobre o seu entorno e sobre as relações dialógicas que se estabelecem entre os agentes sociais deste ecossistema com pretensões de torná-lo educomunicativo. Entra em cena a Educomunicação, termo ressignificado por Ismar de Oliveira Soares ${ }^{2}$, identificado como:

O conjunto das ações inerentes ao planejamento, execução e avaliação de produtos e processos voltados para a criação e desenvolvimento de ecossistemas comunicativos abertos e criativos, em espaços educativos (formais, não formais ou, mesmo, informais), mediados pelas tecnologias da informação, mediante uma gestão democrática e compartilhada de tais recursos, tendo como meta a ampliação do coeficiente comunicativo dos sujeitos e a prática plena da cidadania. (SOARES, 2010, p.7)

A Educomunicação é um campo voltado para as relações entre indivíduos e as formas como estes se comunicam nas práticas educativas. (Soares, 2010).

Soares (2011, p. 45) define "ecossistema comunicativo" como o local de construção de relações dialógicas, em equilíbrio, onde os agentes sociais possam criar

${ }^{2}$ Ismar de Oliveira Soares é Professor livre-docente da Escola de Comunicações e Artes da Universidade de São Paulo - ECA/USP. 
colaborativamente condições ideais para que a Educomunicação possa se estabelecer na perspectiva da participação e do diálogo nas práticas educativas.

\section{Áreas de intervenção social da Educomunicação}

A Educomunicação está ligada à autonomia transformadora e exercício de democracia dos envolvidos, portanto, está em sintonia com os princípios da educação emancipatória e sua ação se consolida em algumas áreas de intervenção, a saber: Educação para a Comunicação (Media education, Media Literacy); Mediação Tecnológica na prática educativa; Expressão Comunicativa através das Artes; Pedagogia da Comunicação; Produção Midiática a serviço da educação; Gestão da Comunicação nos espaços educativos; Reflexão Epistemológica sobre o campo da Educomunicação.

\section{1. Área da Educação para a Comunicação}

Esta área tem "como objeto a compreensão do fenômeno da comunicação, tanto no nível interpessoal e grupal quanto no nível organizacional e massivo. Volta-se para o estudo do lugar dos meios de comunicação na sociedade e seu impacto". (Soares, 2011, p. 47). É considerada como a área da pedagogia da recepção (media education, educación a los medios). No contexto pedagógico é constituída "pelos programas de formação de receptores autônomos e críticos ante os meios". (Soares, 2011a, p. 26).

\section{2. Área de mediação tecnológica na Educação}

A importância desta área está no fato da disseminação das tecnologias tradicionais e emergentes na sociedade atual. Os recursos digitais propiciam a expressão comunicativa na comunidade educativa e garantem a possibilidade de produção e disseminação de conhecimentos e informações. Neste âmbito, a hierarquia existente na relação docente/discente desaparece, pois evidencia-se o auxílio mútuo: os docentes aprendem com seu estudantes e vice-versa. A disseminação das tecnologias de informação e comunicação intensifica o hábito de pesquisas ao permitir acesso às descobertas científicas e conhecimentos de toda ordem, "com a incidência das tecnologias no cotidiano das relações entre as pessoas e a cultura, com grande interferência na prática dos agentes pela agilização dos procedimentos e pelo favorecimento de novos processos 
de aprendizagem" (SOARES, 2010). O modelo de comunicação em rede alterou o sentido das práticas educativas que, quando bem articuladas, nos espaços educativos, permitem a consolidação de ecossistemas educomunicativos. Nesta linha de pensamento e investigação é oportuno incluir a consideração de Mill e Giacometti-Rocha (2017):

\begin{abstract}
Em perspectiva sociocultural, os meios de comunicação exercem controle sobre o modo como os indivíduos se comportam, porque suas características delimitam o funcionamento do ambiente social (MEYROWITZ, 1985, p. 34). [...] Se a informação é um elemento fundamental para dizer ao indivíduo qual é seu lugar na sociedade, no momento em que esses controles são radicalmente alterados, essa perspectiva tende a se transformar ou mesmo desaparecer. Por isso, as mudanças do acesso à Internet e as mudanças de uso dos diferentes tipos de TDIC podem ser importantes para o processo de construção do conhecimento, já que o facilita. Ousa-se, aqui, pensar que essas mudanças podem gerar maior autonomia no sentido de que adolescentes dependem menos do espaço físico e, com o tempo, tendem a depender cada vez menos de um professor presencialmente disponível, conforme as estruturas institucionais tradicionalmente seguidas pela educação brasileira. (GIACOMETTI-ROCHA, 2017, p. 969-970).
\end{abstract}

Desta forma faz-se necessário observar os rumos do uso da tecnologia da informação e comunicação na perspectiva da educação emancipatória no contexto da Educomunicação.

\title{
3. Expressão Comunicativa por meio da Arte
}

Segundo Metzker (2008, p. 12), "Na prática, essa área de intervenção social da Educomunicação diz respeito a atividades geralmente coordenadas por arte-educadores no sentido de garantir espaços de fala, visibilidade e livre expressão dos sujeitos sociais", valoriza as diferentes expressões artísticas e criativas nos espaços educativos “como meio de comunicação acessível a todos". (Soares, 2011, p. 47).

\section{4. Área da Pedagogia da Comunicação}

De acordo com Soares (2011, p. 48), "referenda-se na educação formal (o ensino escolar), pensando-a como um todo". Mantém-se atenta ao cotidiano da didática, prevendo a multiplicação da ação dos agentes educativos (o professor e o aluno trabalhando juntos), optando, quando conveniente, pela ação através de projetos. 
5. Produção Midiática a serviço da educação

As atividades desenvolvidas nesta área solicitam "domínio pleno do conteúdo a ser ensinado, da pedagogia da comunicação que envolve a linguagem midiática escolhida e da técnica de produção". (Almeida, 2016, p.17). As produções finais desta área são criadas com intencionalidade educativa e serão veiculadas nos diferentes meios de comunicação. Logo, o importante é a produção final, e por este motivo tais produtos devem atender a padrões elevados de qualidade. Cabe destacar que as produções amadoras fazem parte da área de intervenção "educação para a comunicação", cujo foco importante é o processo de produção.

6. Área da gestão da comunicação

Área de especial relevância, pois é responsável pelo "planejamento e execução dos planos, programas e projetos referentes às demais áreas de intervenção, apontando, inclusive, indicadores para a avaliação de ecossistemas comunicacionais". (Soares, 2011, p. 48). Ao gestor cabe auxiliar os agentes sociais na escolha das áreas de intervenção, espaços e tecnologias adequadas.

\section{7. Área de reflexão epistemológica}

De acordo com Soares (2011, p. 48), "a área de reflexão epistemológica dedicase à sistematização de experiências e ao estudo do próprio fenômeno constituído pela inter-relação entre Educação e Comunicação, mantendo atenção especial à coerência entre teoria e prática".

Este âmbito é constituído pela reflexão sistemática e metodológica para garantir a integridade e "unicidade às práticas da Educomunicação". (SOARES, 2011a, p. 27).

Estas áreas coexistem e estão conectadas para a efetivação das práticas educomunicativas. Desta feita, cabe aos educomunicadores a observação de que as mesmas não são excludentes e compõem um só campo de interação.

\section{Considerações finais}


A apresentação da Educomunicação, neste texto, como um campo estratégico para subsidiar a formação de professores na perspectiva da educação emancipatória, ou vice-versa, amplia a possibilidade de reciclagens/ações efetivas para docentes e discentes. Vale mencionar que no âmbito das políticas públicas da SME (Secretaria Municipal de Educação), a Educomunicação se faz presente em pelo menos dois relevantes momentos. O primeiro foi na criação do Projeto Educom.Rádio e o segundo foi na criação do Núcleo de Educomunicação da SME.

A Educomunicação propicia, como campo emergente e consolidado, possibilidades de emancipação individual e coletiva em espaços educacionais, com a promoção de valores democráticos, de respeito à diversidade e de crescimento mútuo. A aquisição da autonomia e transformação dos agentes sociais das comunidades educativas torna-se o diferencial e um ideal a ser alcançado com as práticas educomunicativas.

\section{REFERENCIAS}

ALMEIDA, L. B. C. de. Projetos de intervenção em educomunicação. Disponível em:

<https://www.researchgate.net/publication/299533488_Planejando_projetos_de_interve ncao_em_educomunicacao>. Acesso em: 01 jun. 2017

FAGUNDES, M. C. V. A pesquisa como princípio da do-discência. In: ZANCHET, B. M. B. et al. (org.). Processos e práticas na formação de professores: caminhos possíveis. Brasília: Liber Livro Editora, 2011. p. 171-195.

GADOTTI, M. Trabalho e educação numa perspectiva emancipatória. In: II Fórum Mundial de Educação Profissional e Tecnológica: democratização, emancipação e sustentabilidade. Disponível em: <https://goo.gl/bdjJWD>. Acesso em: 01 jun. 2017

GIACOMETTI-ROCHA, E.; MILL, D. Mudanças nas interações sociais e mobilidade na educação com a mediação das Tecnologias Digitais de Informação e Comunicação. Revista Ibero-Americana de Estudos em Educação, Araraquara, v. 12, n. 2, p. $966-$ 982, abr-jun/2017. Disponível em: <http://dx.doi.org/10.21723/iaee.v12.n2.9074>. EISSN: 1982-5587.

Metzker, G. F. R. Educomunicação: o novo campo e suas áreas de intervenção social. In: Intercom - Sociedade Brasileira de Estudos Interdisciplinares da Comunicação XIII Congresso de Ciências da Comunicação na Região Sudeste. 2008. São Paulo. Disponível em: <https://www.scribd.com/doc/16370414/Educomunicacao-o-novocampo-e-suas-areas-de-intervencao-social>. Acesso em: 10 jun. 2017. 
MEYROWITZ, J. No sense of place: the Impact of electronic media on social behavior. London: Oxford University Press, 1985.

SÁNCHEZ GAMBOA, S. Epistemologia da pesquisa em educação. Campinas, Praxis. 1998

SOARES, I. de O. Educomunicação e terceiro entorno: diálogos com Galimberti, Echeverría e Martín-Barbero. Revista Comunicação \& Educação: Revista do Departamento de Comunicações e Artes da ECA/USP, São Paulo, v. 15, n. 3, 2010. Disponível em: <http://www.revistas.usp.br/comueduc/article/view/44845>. ISSN: 2316-9125.

SOARES, I. de O. Educomunicação: o conceito, o profissional, a aplicação: contribuições para a reforma do ensino médio. São Paulo: Paulinas, 2011. (Coleção Educomunicação).

SOARES, I. de O. Educomunicação: um campo de mediações. In: CITELLI, A. O.; COSTA, M. C. C. (orgs). Educomunicações: construindo uma nova área de conhecimento. São Paulo: Paulinas, 2011a. p. 13-28.

VIANA, N. Adorno: educação e emancipação. Disponível em: <http://periodicos.unb.br/index.php/resafe/article/viewFile/5478/4585>. Acesso em: 01 jun. 2017

\section{Como referenciar este artigo}

SANTOS, Isabel Pereira dos. A Formação de Professores na Perspectiva da Educomunicação. Revista on line de Política e Gestão Educacional, Araraquara/SP, v.21, n. esp. 1, p. 640-648, out./2017. Disponível em: <http://dx.doi.org/10.22633/rpge.v21.n.esp1.out.2017.10031>. ISSN: 1519-9029.

Submetido em: 02/07/2017

Aprovado em: 20/09/2017 